\title{
Quaderni
}

QUADERNI Communication, technologies, pouvoir

\section{Communication politique et culture : enjeux paradoxaux de la médiation culturelle impulsée par André Malraux}

\section{Alexandre Eyries}

\section{(2) OpenEdition \\ Journals \\ Édition électronique \\ URL : http://journals.openedition.org/quaderni/769 \\ DOI : $10.4000 /$ quaderni.769 \\ ISSN : 2105-2956 \\ Éditeur \\ Les éditions de la Maison des sciences de l'Homme}

\section{Édition imprimée}

Date de publication : 5 janvier 2014

Pagination : 83-90

Référence électronique

Alexandre Eyries, «Communication politique et culture : enjeux paradoxaux de la médiation culturelle impulsée par André Malraux », Quaderni [En ligne], 83 | Hiver 2013-2014, mis en ligne le 01 janvier 2016, consulté le 30 avril 2019. URL : http://journals.openedition.org/quaderni/769 ; DOI : 10.4000/ quaderni.769 


\section{Politique}

Communication politique et

Bien avant d'être ministre, André Malraux a de tout temps fait de la culture le noyau dur de la plupart de ses interventions car il a bien assimilé que « la médiation fonde la dimension à la fois singulière et collective de notre appartenance culture : enjeux et, au-delà, de notre citoyenneté $»^{1}$. Ces allocutions politiques acquièrent une forte coloparadoxaux de la médiation culturelle impulsée par André Malraux ration culturelle par les citations mystiques ou littéraires, et les références historiques qui les émaillent. En cela, il fait œuvre de médiation en direction de la culture, car " la dimension collective de la culture se manifeste d'abord dans les pratiques culturelles, telles qu'elles apparaissent dans l'espace public $»^{2}$.

\section{La culture au pluriel}

C'est cette dimension collective de la culture qu'André Malraux retient car elle crée du lien social. Les pratiques culturelles structurent l'espace public et créent une identité collective autour de valeurs. Il a développé une compréhension fine des enjeux mobilisés par les pratiques culturelles qui, dans l'espace

Alexandre Eyries

Laboratoire I3M Université de Nice de la représentation, mettent en œuvre une dialectique symbolique $\mathrm{du}$ singulier et $\mathrm{du}$ collectif : "la culture n'existe comme fait total qu'en raison de sa manifestation comme expression d'une expérience individuelle $»^{3}$. En effet si la création est pour chaque artiste nécessairement solitaire, la réception passe toujours par le filtre d'une subjectivité, celle du regardeur pour Pierre Soulages. Chaque œuvre est perçue, interprétée par des individus singuliers. La théorie malrucienne du choc esthétique suppose que chaque personne connaisse une rencontre intime avec une œuvre avec laquelle elle noue un dialogue interprétatif. 
Pour que chacun puisse rencontrer des œuvres, « il faut [....] qu'il y ait, dans la cité, des acteurs de la médiation culturelle, dont les pratiques et les stratégies s'inscrivent dans une logique esthétique ${ }^{4}$. C'est ainsi qu'André Malraux conçoit une médiation culturelle qui ne peut pas se contenter d'un modèle descendant et a besoin, pour conquérir une certaine efficacité, de s'appuyer sur des relais chargés de propager la culture populaire, de la médiatiser. Les pratiques des médiateurs culturels constituent alors la transcription concrète d'une politique novatrice. La démocratisation culturelle est au service d'une conception exigeante de la démocratie. La culture chez Malraux est toujours en mouvement, elle ouvre toujours des perspectives inédites. Elle demande de l'énergie et une forte implication pour résister à tout ce qui la menace : «art, pensées, poèmes, tous les vieux rêves humains, si nous avons besoin d'eux pour vivre, ils ont besoin de nous pour revivre. Besoin de notre passion, besoin de nos désirs besoin de notre volonté $»{ }^{5}$. Les diverses formes de la culture sont aussi essentielles à l'homme que l'air qu'il respire. Les œuvres sont animées par un souffle propre qui aide l'humanité à (mieux) vivre : «les pratiques culturelles sont des pratiques sociales engagées dans l'espace public $»^{6}$, comme l'écrit Bernard Lamizet. C'est parce que la culture aide l'homme à vivre libre et avec dignité que les pratiques culturelles contribuent à renforcer l'adhésion à un projet de vie en collectivité : "les faits culturels ne font apparaître le peuple et la sociabilité que par la médiation de la signification ${ }^{7}$. Les œuvres culturelles ont en retour besoin de l'homme (de ses affects, de ses sensations) pour ressusciter des siècles après. Les œuvres de la culture mondiale ont besoin, et c'est le point d'orgue de la pensée culturelle d'André Malraux, de faire l'objet d'une médiation intellectuelle et culturelle en direction du grand public.

C'est donc de la médiation culturelle que je tenterais à présent de donner la définition la plus précise et la plus pertinente possible. Dans son ouvrage qui fait autorité (La médiation culturelle), Bernard Lamizet, la définit de la manière suivante: "la société ne peut exister que si chacun de ses membres a conscience d'une relation dialectique nécessaire entre sa propre existence et l'existence de la communauté : c'est le sens de la médiation, qui [...] fonde symboliquement les structures politiques et institutionnelles du contrat social $»^{8}$.

La médiation selon Bernard Lamizet est constitutive de la vie en société. Elle socialise et fonde la citoyenneté : « c'est à cette échelle qu'il convient de prendre la mesure de l'importance des politiques culturelles : il s'agit de fonder [...] la citoyenneté même qui constitue le lien social dans sa dimension [...] anthropologique »". Elle constitue un interprétant de la société et de ses structures anthropologiques. La culture étant caractéristique d'une langue et d'une nation, elle contribue à tisser des synergies entre les divers membres d'une communauté.

Michèle Gellereau rappelle que si les pratiques culturelles ont vocation à être « étudiées en Sciences de l'information et de la communication sous des angles différents, selon les objets auxquels le chercheur s'intéresse (industries culturelles, culture médiatique, lieux d'exposition, etc.) et selon les approches qui 
seront privilégiées (socio-économie, analyse de discours, sémiologie, anthropologie, etc.) ${ }^{10}$, c'est en raison de la multi-modalité de leurs approches. Comment alors conceptualiser précisément la médiation culturelle, ses différentes acceptions et catégories ? Michèle Gellereau propose la définition suivante : «la médiation culturelle désigne souvent les actions d'accompagnement et la construction de dispositifs d'interprétation des auvres pour des publics, l'espace de production d'objets culturels et de langages qui produisent du sens et des liens... ${ }^{11}$.

\section{Aux origines de la médiation culturelle malrucienne}

L'action d'André Malraux au service de la culture démarre bien avant son mandat de ministre, dès sa période indochinoise puis antifasciste. Lors de sa conférence intitulée «L'homme et la culture», André Malraux pose les bases de ce qui sera théorisé plus tard sous le terme de médiation culturelle : « tout art est une leçon par ses dieux. Car l'homme crée ses dieux avec tout lui-même, mais il crée son art le plus haut avec le monde réduit à l'image de son secret toujours le même : faire éclater la condition humaine par des moyens humains ${ }^{12}$. La médiation culturelle revient à accompagner les œuvres de dispositifs sociotechniques d'information et de communication pour les mettre en valeur et les préserver. Si « l'homme ne naît pas de sa propre affirmation, mais de la mise en question de l'univers ${ }^{13}$, alors la médiation culturelle consiste donc pour l'homme à se doter de lois pour encourager la création artistique.
Dans son ouvrage, Bernard Lamizet rappelle que « la culture représente une part de vérité pour ceux qui y adhèrent, mais elle ne représente qu'un système de formes pour ceux qui s'en tiennent à distance ${ }^{14}$. Ce propos montre bien l'ambivalence des conceptions qu'engendre la culture qui se constitue comme une ligne de partage symbolique entre le (ou les) public (s) et la (ou les) culture (s) qui s'affirment comme des univers imperméables.

La médiation se traduit par «la volonté de construire ou de restaurer des liens, [...] de réparer la séparation entre cultures et publics $»^{15}$. Cette volonté de remettre la culture au service (du) public semble être une constante de la médiation culturelle. La médiation, c'est en définitive ce qui permet aux œuvres de trouver un public et d'entamer un dialogue fécond avec lui. Les notions essentielles de passage et de lien se couplent, dans le champ de la médiation culturelle, avec celle de démocratisation culturelle (qui repose sur le constat de la fragmentation des publics et, sur la volonté de les faire communiquer entre eux). La médiation constitue une vision mobilisatrice de la culture : « la médiation représente l’impératif social majeur de la dialectique entre le singulier et le collectif, et de sa représentation dans des formes symboliques $»^{16}$.

Proposant de penser cette pratique comme une utopie scientifique et intellectuelle, Bernard Lamizet construit une vision théorique idéale de la médiation culturelle. Dans son rapport à la culture, André Malraux - qui a répété pendant des années qu'il détestait les experts et les mandarins de toutes sortes - était animé 
par une conception similaire de la culture qu'il s'est efforcé de démocratiser. Par ce biais, la médiation culturelle contribue à créer du lien social : «les pratiques culturelles mettent en scène le lien social dans l'espace public en lui donnant des formes et des langages qui rendent possibles l'identification, le transfert et l'adhésion du public ${ }^{17}$.

La médiation culturelle malrucienne consiste donc à mettre en scène la culture dans l'espace public élargi. Les racines gréco-latines de la culture judéo-chrétienne constituent la base même de toute médiation culturelle. C'est le sens de l'hommage qu'il a adressé à la Grèce le 28 mai 1959, affirmant que la culture devait être considérée comme un patrimoine universel inculqué à l'humanité tout entière : "on ne saurait trop le proclamer : ce que recouvre pour nous le mot si confus de culture - l'ensemble des créations de l'art et de l'esprit-, c'est à la Grèce que revient la gloire d'en avoir fait un moyen majeur de formation de l'homme $"{ }^{18}$. Rendant hommage à la Grèce, André Malraux prend soin de saluer en elle l'origine d'une part majeure de la culture mondiale qui fonde "la citoyenneté même qui constitue le lien social dans sa dimension politique et anthropologique $»{ }^{19}$. La médiation culturelle permet ainsi de fonder une citoyenneté mondiale qui repose sur une politique d'initiation à la culture. Dans cette lignée, Jean Caune propose une analyse éclairante : "l'anthropologie [...] fait de la culture une totalité qui se manifeste par des formes de relation et de discours qui échappent à l'intentionnalité et à l'activité de l'homme ${ }^{20}$.

Avec André Malraux, la médiation culturelle acquiert une dimension anthropologique et éclaire la complexité de la condition humaine : « les faits culturels construisent un espace public culturel $»^{21}$ mondialisé. Conscient de la fonction éducative de la médiation culturelle, il rappelle que « c'est par la première civilisation sans le livre sacré, que le mot intelligence a voulu dire interrogation. L'interrogation dont allait naître la conquête du cosmos par la pensée, du destin par la tragédie, du divin par l'art et par l'homme $»^{22}$.

Dans le cadre pourtant protocolaire de son mandat, il prend la liberté de dévoiler tout ce qu'il doit à la Grèce dans la construction de sa pensée et de sa culture : «vieilles nations de l'esprit, il ne s'agit pas de nous réfugier dans notre passé, mais d'inventer l'avenir qu'il exige de nous. Au seuil de l'ère atomique, une fois de plus, l'homme a besoin d'être formé par l'esprit ${ }^{23}$. La médiation culturelle malrucienne est un pari osé qui s'appuie sur une solide éducation à la culture qui est ce qui reste lorsque l'on a tout oublié selon la célèbre formule d'Edouard Herriot ${ }^{24}$.

Pour Malraux, la culture - beaucoup plus que la maîtrise technologique - est la clé du monde de demain. Il affirme que le problème majeur qui se pose au monde contemporain c'est « de rendre accessibles les plus grandes ouvres au plus grand nombre d'hommes ${ }^{25}$.

\section{La Maison de la culture, fer de lance de la médiation culturelle?}

C'est dans ce projet de démocratisation culturelle qu'il faut rechercher l'origine du 
projet de Maisons de la culture dont la première a vu le jour en 1961 au Havre. Cinquante-deux ans après l'ouverture de cette première Maison, il convient d'interroger la postérité de ce projet. Le 17 novembre 1959, Malraux prononce un discours pour présenter le budget des Affaires Culturelles et, à cette occasion, expose pour la première fois son projet de Maisons de la culture : « il faut que, par ces maisons de la culture qui, dans chaque département français, diffuseront ce que nous essayons de faire à Paris, n'importe quel enfant de seize ans, si pauvre soit-il puisse avoir un véritable contact avec son patrimoine national et avec la gloire de l'esprit de l'humanité ${ }^{26}$.

La vocation de ces Maisons est de mettre en relation la culture et les publics qui en sont éloignés : "les pratiques culturelles mises en cuvre dans l'espace de la représentation mettent en cuvre une dialectique symbolique $d u$ singulier et $d u$ collectif $»^{27}$. Elle est un lieu pluridisciplinaire (« religion en moins, les Maisons de la culture sont les modernes cathédrales ${ }^{28}$ ) où les citoyens vont pouvoir rencontrer l'art. Cet ambitieux projet est un parfait exemple de médiation culturelle qui façonne «les formes culturelles d'appartenance et de sociabilité en leur donnant un langage et en leur donnant les formes et usages par lesquels les acteurs de la sociabilité s'approprient les objets constitutifs de la culture ${ }^{29}$.

Ce projet fut dans l'ensemble une réussite, même si l'on doit admettre que le projet initial, qui prévoyait la création de quatre-vingt-quinze Maisons, n'en a vu ouvrir que sept (au Havre, à Bourges, Thonon, Amiens, Grenoble, Bobigny et Nevers), dont quatre seulement ont gardé le leur nom originel..

Le but de ces Maisons de la culture était à l'origine de transformer un privilège (la culture) en un bien commun qui donne « à la culture une consistance perceptible et la matérialité sensible d'une prestation réelle $»^{30}$. En 1991, Bertrand Faivre d'Arcier a regroupé les Maisons de la culture, les centres d'animation et de développement culturel au sein de soixante-dix Scènes nationales qui pratiquent la pluridisciplinarité et la décentralisation voulues par André Malraux, et participent au développement culturel de leur ville en devenant des lieux de production et de diffusion de la création contemporaine (musique, danse, théâtre, art, etc.).

Ceci suffit à prouver que le concept de Maison de la culture - toujours vivace de nos jours - ne se limite pas aux sept « Maisons » originelles et nourrit la philosophie de nombreuses institutions culturelles en France et dans le monde (Belgique, Canada, Inde, etc.). C'est en cela que réside la plus belle réussite de ce projet utopique et magnifique initié par André Malraux. C'est également là que réside le paradoxe fondateur d'une forme de médiation culturelle (géniale et prophétique) qui a atteint ses objectifs et su s'imposer malgré l'apparent échec initial.

$\mathrm{Au}$ terme de cet article, il apparaît que, là encore, André Malraux a fait preuve d'un réel talent de visionnaire et a considérablement renouvelé les modalités de mise en relation et d'interconnexion de la communication, de la politique et de la culture. 


\section{$R \cdot \dot{E} \cdot F \cdot \dot{E} \cdot R \cdot E \cdot N \cdot C \cdot E \cdot S \quad N \cdot O \cdot T \cdot E \cdot S$}

CAUNE J., Culture et communication. Convergences théoriques et lieux de médiation, Grenoble, PUG, 1999.

GELLEREAU M., « Pratiques culturelles et médiation " dans Stéphane Olivesi (dir.), Sciences de l'information et de la communication. Objets, savoirs, discipline, Grenoble, PUG, 2009.

LAMIZET B., La médiation culturelle, Paris, L'Harmattan : collection « Communication et Civilisation », 1999.

MALRAUX A., La politique, la culture, Paris, Gallimard : collection Folio Essais, 1996.
1. Bernard Lamizet, La médiation culturelle, Paris, Éditions L'Harmattan : collection « Communication et Civilisation », 1999, p. 9.

2. Jean Caune, Culture et communication. Convergences théoriques et lieux de médiation, op.cit., p. 5. 3. Jean Caune, Culture et communication. Convergences théoriques et lieux de médiation, op.cit., p. 7. 4. Bernard Lamizet, La médiation culturelle, op.cit., p. 17.

5. André Malraux, «L'œuvre d'art. Discours prononcé au Congrès international des écrivains pour la défense de la culture, tenu à Paris du 21 au 25 juin $1935 »$ dans André Malraux. La politique, la culture, op.cit., p. 121. 6. Bernard Lamizet, La médiation culturelle, op.cit., p. 22.

7. Bernard Lamizet, La médiation culturelle, op.cit., p. 22.

8. Bernard Lamizet, La médiation culturelle, op.cit., p. 9.

9. Ibid., pp. 9-10.

10. Michèle Gellereau, «Pratiques culturelles et médiation » dans Stéphane Olivesi (dir.), Sciences de l'information et de la communication. Objets, savoirs, discipline, Grenoble, PUG, 2009, p. 27.

11. Michèle Gellereau, "Pratiques culturelles et médiation ", op.cit., p. 28.

12. André Malraux, "L'homme et la culture » dans André Malraux. La politique, la culture, op.cit., p. 160. 13. André Malraux, «L'homme et la culture», op.cit., p. 161.

14. Bernard Lamizet, La médiation culturelle, Paris, L'Harmattan : collection « Communication et Civilisation », 1999, p. 13.

15. Michèle Gellereau, «Pratiques culturelles et médiation », op.cit., p. 31. 
16. Bernard Lamizet, La médiation culturelle, op.cit., p. 9.

17. Bernard Lamizet, La médiation culturelle, op.cit., p. 282.

18. André Malraux, "Hommage à la Grèce » dans André Malraux. La politique, la culture, op.cit., p. 256. 19. Bernard Lamizet, La médiation culturelle, op.cit., p. 10 .

20. Jean Caune, Culture et communication. Convergences théoriques et lieux de médiation, op.cit., p. 163. 21. Ibid., p. 21.

22.André Malraux, « Hommage à la Grèce », op.cit., pp. 256-257.

23. André Malraux, « Hommage à la Grèce », op.cit., p. 258.

24. Dans ses Notes et maximes.

25. André Malraux, « Hommage à la Grèce », op.cit., p. 257.

26. http://www.assemblee-nationale.fr/histoire/Andre Malraux/discours/Malraux_17nov1959.asp.

27. Bernard Lamizet, La médiation culturelle, op.cit., p. 19.

28.http://www.charles-de-gaulle.org/pages/1-homme/ dossiers-thematiques/1958-1970-la-ve-republique/ de-gaulle-et-la-culture/documents/andre-malrauxa-lrsquoassemblee-nationale--27-octobre-1966.php. 29. Bernard Lamizet cité dans Michèle Gellereau, "Pratiques culturelles et médiation », op.cit., p. 33.

30. Bernard Lamizet, La médiation culturelle, op.cit., p. 15 . 
